\title{
Determinants of Nursing Students' Confidence in Peripheral Intravenous Catheter Insertion and Management
}

\author{
Ferika Indarwati ${ }^{1 *}$, Yanuar Primanda ${ }^{2}$ \\ ${ }^{1}$ Department of Pediatric Nursing, School of Nursing, Faculty of Medicines and Health Sciences, Universitas Muhammadiyah \\ Yogyakarta, Yogyakarta, Indonesia; ${ }^{2}$ Department of Adult Nursing, School of Nursing, Faculty of Medicines and Health \\ Sciences, Universitas Muhammadiyah Yogyakarta, Yogyakarta, Indonesia
}

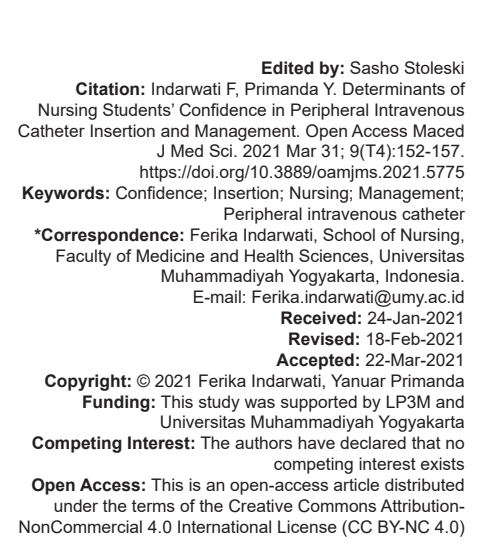

\section{Introduction}

It is estimated that nearly $90 \%$ of hospitalized adult patients require peripheral intravenous catheter (PIVC) inserted to receive medications, making PIVC insertion and care the most frequent invasive procedure undertaken, particularly by nurses [1]. Despite its crucial functions to help patients' recoveries, PIVC failure and complications in adult patients are still relatively high, with $34 \%$ of PIVC insertion failure before the completion of the intravenous therapy [2]. This failure costs not only the patients but also the healthcare systems. The average cost per PIVC procedure and care are predicted to be $\$ 69$ in the US and $\$ 237$ in Switzerland [3], [4], [5]. Reinsertion procedures can increase pain and anxiety in patients [6], [7]. The pain related to medical procedures experienced by patients during their hospitalizations increases medical fear and procedural pain perceptions, resulting in a reluctance to seek medical care [8].

\begin{abstract}
BACKGROUND: Peripheral intravenous catheter (PIVC) is one of the medical devices commonly inserted in hospitalized patients, both adults and pediatrics. PIVC has crucial functions for delivering drugs, fluids, blood transfusions, and diagnostic tests for patients. Thus, nursing students must be confident in terms of insertion and management of this device. However, studies assessing nursing students' confidence and its determinants are still
\end{abstract}

AIM: This study aims to examine the internship nursing student's confidence in PIVC insertion and management in

METHODS: A cross-sectional study was conducted to measure internship nursing students' confidence in PIVC tudents in Yogyakarta were recruited, and a 5-point Likert scale questionnaire consisting of 19 questions was used estimates of the potential factors with students' confidence.

LTS: Results indicated that the internship nursing student's confidence score ranged from 57 to 95, with and direct observation of procedural skill assessment of PIVC insertion and care $(p<0.05)$. The general linear analysis showed that only bedside teaching and interaction of bedside teaching and direct observation procedural care $(\beta=10.99,95 \%$ confidence interval $[\mathrm{Cl}] 2.00-20.00$ and $\beta=13.15,95 \% \mathrm{Cl} 1.20-25.15, \mathrm{p}<0.05$, respectively).

CONCLUSION: This result indicated that nursing students need direct simulation and assessment of PIVC insertion and care to the patients to improve their confidence in PIVC insertion and management in adult patients.
As the frequent inserters of PIVC, nurses play a significant role in preventing PIVC failure and complications. Therefore, it is paramount that nurses have sufficient knowledge, confidence, and PIVC insertion and care skills. Nurses' competency related to intravenous catheter insertion, use, and care has played an essential role in preventing catheter complications. The Infusion Nursing Society has mentioned that catheter use and care standardization and nurse education and training are vital to optimize peripheral catheter outcomes [9]. Furthermore, health providers expect that graduate nursing students are competent in clinical skills, such as in PIVC insertion and maintenance, to reduce patient safety risks. Therefore, nursing education institutions are responsible for preparing their students to have sound knowledge, confidence, and skill in PIVC insertion and care.

Nevertheless, PIVC placement and care are two of the most challenging skills taught in schools of nursing. To master this skill and prevent unforeseeable PIVC failure and complications, students require knowledge of 
the PIVC insertion and care and techniques in performing such invasive procedures and require confidence that can be achieved through many exposures in the clinical learning environment. Confidence has been identified as one of the most important factors supporting nurses in making appropriate decisions in patient care [10], [11]. Several studies reported that nurses with higher selfreported confidence score had faster insertion time, less first insertion failure, and better PIVC outcomes compared to those with lower confidence scores [12].

To improve nursing students' confidence in PIVC insertion and care, nursing students will benefit from better education and a greater PIVC insertion practice volume. Very few studies investigate the influence of teaching-learning programs on students' confidence in PIVC insertion and care. Several studies have found that a blended simulation-based teaching program significantly increased students' self-confidence in PIVC insertion [13]. Similarly, a study conducted by Keleekai et al. (2016) in the USA found that nurse's knowledge, confidence, and skills improve significantly after following the blended PIVC insertion training programs that incorporate three simulation practices. Lack of training has been recognized to affect inserter performances, such as selecting proper IV sizes and insertion sites, failing to recognize catheter complications, and complying with guidelines [14]. Nonetheless, the aforementioned studies focused only on PIVC insertion confidence but not the confidence in PIVC care. Successful outcomes of PIVC placement depend not only on the insertion phase but also on its care/maintenance. The maintenance phase is crucial to prevent PIVC complications, such as phlebitis, to prevent premature PIVC removal, and to assure that the catheter does not fail before completing therapy [15].

In our system, the $5^{\text {th }}$ year nursing students are placed in hospitals to obtain a real-world caring patient experience. We called this year an internship year for students. A clinical learning and teaching program called preceptorship incorporating bed side teaching, meet the expert lecture, direct observation procedural skills (DOPSs), supervised clinical examination is implemented during this internship period particularly to address gaps in the internship nursing students' clinical skills. However, there are very limited studies investigating the influence of these learning strategies to enhance students' confidence in performing technical skills frequently undertaken by nurses, such as PIVC insertion and care. Therefore, this study examines the internship nursing student's confidence in PIVC insertion and management in adult patients and factors contributing to the students' confidence.

\section{Methods}

A cross-sectional design with an online survey approach was conducted to investigate the internship nursing students' confidence in the insertion and maintenance of PIVC in adult patients in Yogyakarta, Indonesia. Clinical teaching components, such as students' engagement in PIVC expert lecture, bedside teaching, DOPS, frequency of undertaking PIVC insertion and care with preceptor supervisions, gender, and number of internship stages (the internship program has 9 stages) passed by students, which may influence students' confidence, were also measured. A cross-culturally adapted and validated questionnaire consisted of 19 questions to measure students' confidence in PIVC insertion and care. Each scored on a 5-point Likert scale with the following descriptors: 1 = strongly disagree, 2 = disagree, $3=$ neither disagree nor agree, 4 = agree, and $5=$ strongly agree. The maximum score was 95 and the minimum score was 19. Cronbach's alpha value was $0.85(\alpha=0.85, n=22)$, with individual item alphas ranging from 0.81 to 0.86 ( $\alpha=0.81-0.86, \mathrm{n}=22$ ). This study's ethics approval was obtained from the Institutional Review Board with ethics approval number of 177/EC-KEPK FKIK UMY/ $\mathrm{VII} / 2020$. The student's participation in this study was totally voluntarily and will not influence student's academic performance.

SPSS $^{\text {TM }}$ version 26 was utilized to analyze data. Variables examined in this study were presented as frequency and percentage or as mean $\pm S D$ depending on the variables' type and data distribution. Mann Whitney and Kruskal-Wallis test was utilized to investigate the association of the internship nursing student confidence on PIVC insertion and maintenance with students engagement in PIVC expert lecture, bedside teaching, DOPS, assisting PIVC insertion and care, gender, and number of internship stages (the internship program has 9 stages) passed by students. A general linear regression analysis was performed to obtain adjusted estimates of the potential factors with students' confidence. Only factors that were found significantly associated with the students' confidence in the univariate analysis were included in the adjusted model. Results were expressed as relative risk and 95\% confidence intervals (Cls). Statistical significance was set at $<0.05$ for all analysis conducted in this study.

\section{Results}

The study was conducted between April and June 2020. Out of 109 nursing students invited in this research, only 100 students completed the online survey (response rate: 91\%). Table 1 shows the descriptive statistics of the variable included in this study. More than two-thirds $(78,78 \%)$ of the participating students were female, and $56(56 \%)$ of the respondents had passed three internship stages. Most of the students engaged in PIVC expert lecture 78 (78\%), bedside teaching 88 
Table 1: Demographic, clinical teaching components, and students' confidence

\begin{tabular}{ll}
\hline Variable & Value (n: 100$)$ \\
\hline Gender & \\
Male & $22(22 \%)$ \\
Female & $78(78 \%)$ \\
Internship stages passed & \\
$\quad$ Three stages & $56(56 \%)$ \\
Four stages & $25(25 \%)$ \\
$\quad$ Five stages & $19(19 \%)$ \\
Expert lecturer & \\
$\quad$ No & $22(22 \%)$ \\
Yes & $78(78 \%)$ \\
Bedside teaching & \\
$\quad$ No & $12(12 \%)$ \\
Yes & $88(88 \%)$ \\
Direct observational procedural skills & \\
$\quad$ No & $16(16 \%)$ \\
Yes & $84(84 \%)$ \\
Undertaking PIVC insertion and care under preceptor supervision \\
$\quad \leq 2$ times & $10(10 \%)$ \\
$3-5$ times & $48(48 \%)$ \\
$\geq 6$ times & $42(42 \%)$ \\
Students confidence & $75.2( \pm 8.1)$ \\
\hline PIVC: Peripheral intravenous catheter. &
\end{tabular}

(88\%), and DOPS $84(84 \%)$. In our system, students are scheduled (they are not in the same stages) so some of the students may not finish all of their clinical stages (5 stages), this explains why some of them were not having those clinical teaching activities recorded yet. Almost half of the students had 3-5 times of experience doing PIVC insertion and care by themself in a supervised learning environment. The mean score of the nursing student's confidence in PIVC insertion and care was $75.2( \pm 8.1)$.

The students' mean confidence score, as shown in Table 2, was significantly different, particularly for students who engaged in bedside teaching and DOPS compared to those who did not participate in any of the bedside teaching or DOPS ( $p: 0.037$ and 0.044, respectively).

Table 2: Mean difference of the students' confidence score across different categories of the clinical components

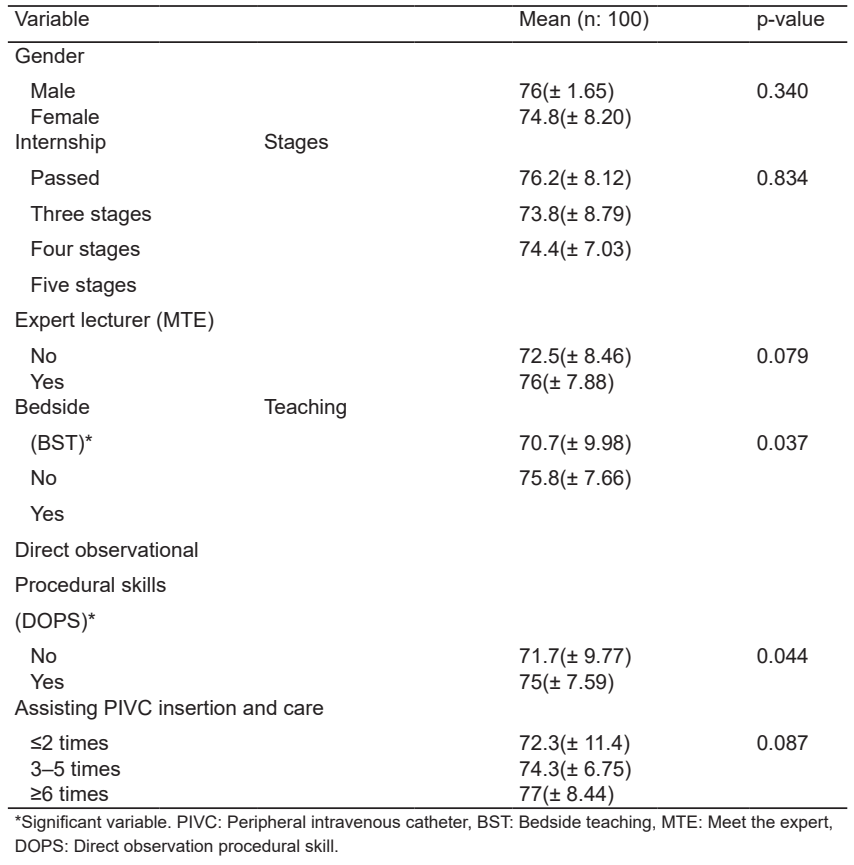

The adjusted analysis in Table 3 indicated that bedside teaching and interaction between bedside
Table 3: The adjusted analysis of the clinical teaching components and internship nursing students' confidence in PIVC insertion and management

\begin{tabular}{|c|c|c|c|c|}
\hline Variable & Estimates & $95 \% \mathrm{Cl}$ & $\mathrm{t}$ & $\mathrm{p}$-value \\
\hline $\begin{array}{l}\text { (Intercept) } \\
\text { BST }\end{array}$ & 76.32 & $(74.60-78.03)$ & 87.98 & $<0.001$ \\
\hline $\begin{array}{l}\text { Yes-No* } \\
\text { DOPS }\end{array}$ & 10.99 & $(1.88-20.10)$ & 2.39 & 0.019 \\
\hline $\begin{array}{l}\text { Yes-No* } \\
\text { BST*DOPS }\end{array}$ & 6.04 & $(-0.07-12.14)$ & 1.96 & 0.053 \\
\hline No-Yes and No-Yes* & 13.15 & $(1.15-25.14)$ & 2.17 & 0.032 \\
\hline
\end{tabular}

teaching and DOPS were significant predictors of the student's confidence score $(p<0.005)$, explaining $7 \%$ of the data variance. When the DOPS and interaction between bedside teaching and DOPS were held constant, the coefficients would indicate that students who engaged in PIVC bedside teaching had better confidence in PIVC insertion and care compared to students who did not have bedside teaching in PIVC insertion and care $(10.99,95 \% \mathrm{Cl} 1.87-20.10)$.

\section{Discussion}

Our findings indicated that the students' had low to moderate confidence to perform PIVC insertion and care in adult patients. Similar findings were reported by a study conducted in Malaysia that most nursing students were not entirely confident in performing invasive procedures on patients [16]. A study conducted in the US also reported that students' baseline confidence in their study was also relatively low. The student's confidence might affect their ability to perform PIVC insertion and maintenance procedures to the patients. Furthermore, students' self-confidence was also significantly associated with their clinical practices' understanding and success. This will subsequently affect students in accepting their role as a nurse [17]. Thus, the clinical teaching and learning program is vital components in nursing education to train nursing students to be competent and professional nurses.

At present, the clinical preceptorship education program that incorporated bedside teaching and direct observational procedural skills assessment was emphasized in nursing education [18], [19], [20]. This education model provided opportunities for students to obtain high exposures in clinical settings as well as learning in a safe, supportive environment. According to the study results, students who participated in bedside teaching had better confidence scores than those who did not participate. Bedside teaching was seen as one of the most essential components of medical as well as nursing education. It provided students with an opportunity to learn invasive procedural skills, such as undertaking PIVC insertion and care directly, and how it was directly performed by their preceptor/mentor to the patients [18], [21], [22], [23]. 
A study conducted in new graduated nursing students about their perceptions of the effects of clinical simulation on their critical thinking, learning, and confidence suggested that nursing students trained through direct simulation methods such as bedside teaching had more confidence in patients' care [24]. An experimental study conducted in nursing students using pre-test and post-test design on the influence of a clinical simulation elective on baccalaureate nursing student clinical confidence also showed a significant increase of the students' confidence scores in the intervention group, particularly in diagnosis, patient assessment, nursing, and evaluating compared to the control group [25]. An intervention study conducted assessing nursing students of performance level reported that there was a significant increase on the student's self-confidence who were trained through direct simulation compared to the group who were trained using traditional model [26]. A study on the effect of simulation learning on critical thinking and self-confidence when incorporated into an electrocardiogram nursing course also observed similar findings that nursing students' self-confidence increased significantly following simulation programs in addition to lectures compared to those without direct simulation [27].

Direct stimulation to patients with supervision from preceptors/mentors in clinical nursing education provided a supportive environment for students to apply concepts and skills learned within the nursing curriculum which will subsequently increase their decisionmaking ability and skills essential for nursing care practices [28], [29]. In addition, it also provided a safe environment for students to apply their clinical judgment without posing a greater risk for patients [28], [30]. It is suggested that bedside teaching and DOPS are an approach to clinical education methods and are preferred over the traditional unstructured clinical learning model [21], [23], [31].

Findings in this study also suggested that DOPS is one of the clinical education methods that may benefit students in improving their confidence in PIVC insertion and care. Direct observation of procedural skills is a tool designed for performance-based assessment of clinical skills [20]. DOPS, like bedside teaching, is considered an excellent way of learning in clinical settings. Students are directly observed and assessed with a structured checklist while performing a clinical procedure on actual patients. At the end of the procedure, constructive feedback, both in verbal and written form, is given to the students to identify the areas of strength and areas that need improvement [32]. The DOPS method significantly impacts students' understanding of their weaknesses in both short- and long-term procedural processes [32].

Bedside teaching and DOPS are considered ways to give students hands-on clinical experience, such as acquiring PIVC insertion and care skills [18], [32]. In one study, direct hands-on learning like DOPS was an essential factor in students' learning programs in building students' confidence [25]. Similar findings were reported by another study that there was a significant correlation between the frequencies a skill was performed and the confidence level of the student [33]. A study assessing students "confidence and the frequency of direct observation conducted also indicated that students" confidence in performing procedural skills was significantly related with the number of DOPSs they performed during their clinical placement [34]. It is suggested that students who obtained more direct observation from their mentor may have been engaging in those skills more often, resulting in better confidence and better clinical performance [35]. Logically, the students' hands-on experience is essential in building students' confidence. However, it is also worth noting that the quality of the direct observation of procedural skills (DOPSs) approach will also determine the clinical education outcomes such as nursing students' confidence on PIVC insertion and care [34].

\section{Conclusion}

Our findings suggested that bedside teaching and DOPS seemed to be an excellent education strategy to be implemented in clinical nursing education settings to improve students' confidence and their skills to perform clinical procedures such as PIVC insertion and maintenance. Therefore, nursing education institutions may consider applying these methods into their internship program. However, it should also be noted that bedside teaching and DOPS processes require considerable enthusiasm and commitment from preceptors/mentors, students, and patients' willingness to cooperate, which play a crucial role in this educational method.

\section{References}

1. Aexandrou E, Ray-Barruel G, Carr PJ, Frost S, Inwood S, Higgins $\mathrm{N}$, et al. Use of short peripheral intravenous catheters: Characteristics, management, and outcomes worldwide. J Hosp Med. 2018;13(5):1-7. https://doi.org/10.12788/jhm.3039 PMid:29813140

2. Marsh N, Webster J, Larson E, Cooke M, Mihala G, Rickard CM. Observational study of peripheral intravenous catheter outcomes in adult hospitalized patients: A multivariable analysis of peripheral intravenous catheter failure. J Hosp Med. 2018;13(2):83-9. https://doi.org/10.12788/jhm.2867 PMid:29073316

3. Kokotis K. Cost containment and infusion services. J Infus Nurs. 2005;28(3S):S22-32

PMid:15965377 
4. PierceCA,BakerJJ.Anursing process model:Quantifying infusion therapy resource consumption. J Infus Nurs. 2004;27(4):23244. https://doi.org/10.1097/00129804-200407000-00008 PMid: 15273630

5. Goff DA, Larsen P, Brinkley J, Eldridge D, Newton D, Hartzog T, et al. Resource utilization and cost of inserting peripheral intravenous catheters in hospitalized children. Hosp Pediatr. 2013;3(3):185-91. https://doi.org/10.1542/hpeds.2012-0089 PMid:24313085

6. Scott-Warren V, Morley R. Paediatric vascular access. BJA Educ. 2015;15(4):199-206. https://doi.org/10.1093/bjaceaccp/ mku050

7. Kennedy RM, Luhmann J, Zempsky WT. Clinical implications of unmanaged needle-insertion pain and distress in children. Pediatrics. 2008;122 Suppl 3:S130-3. https://doi.org/10.1542/ peds.2008-1055e

\section{PMid:18978006}

8. Jones T, DeMore M, Cohen LL, O'Connell C, Jones D. Childhood healthcare experience, healthcare attitudes, and optimism as predictors of adolescents' healthcare behavior. J Clin Psychol Med Settings. 2008;15(3):234-40. https://doi.org/10.1007/ s10880-008-9126-7

PMid:19104968

9. Gorski L, Hadaway L, Hagle ME, McGoldrick M, Orr M. Doellman D. for Infusion Nurses Society. Infusion therapy standards of practice. J Infus Nurs. 2016;39(Suppl 1):S1-59.

10. Sabri A, Szalas J, Holmes KS, Labib L, Mussivand T. Failed attempts and improvement strategies in peripheral intravenous catheterization. Biomed Mater Eng. 2013;23(1-2):93-108. https://doi.org/10.3233/bme-120735

PMid:23442240

11. Hagbaghery MA, Salsali M, Ahmadi F. The factors facilitating and inhibiting effective clinical decision-making in nursing: A qualitative study. BMC Nurs. 2004;3(1):2. https://doi. org/10.1186/1472-6955-3-2

PMid: 15068484

12. Farrell C, McCulloch E, Bellhouse S, Delahoyde MK, Hill S, Rickard C, et al. Peripheral cannulae in oncology: Nurses confidence and patients' experiences. Cancer Nurs Pract. 2017;16(3):32-8. https://doi.org/10.7748/cnp.2017.e1408

13. Valizadeh L, Amini A, Fathi-Azar E, Ghiasvandian S, Akbarzadeh B. The effect of simulation teaching on baccalaureate nursing students' self-confidence related to peripheral venous catheterization in children: A randomized trial. J Caring Sci. 2013;/2(2):157-64.

PMid:25276722

14. Hartman JH, Baker J, Bena JF, Morrison SL, Albert NM. Pediatric vascular access peripheral IV algorithm success rate. J Pediatr Nurs. 2018;39:1-6. https://doi.org/10.1016/j.pedn.2017.12.002 PMid:29525210

15. Rickard CM, Webster J, Wallis MC, Marsh N, McGrail MR, French $\mathrm{V}$, et al. Routine versus clinically indicated replacement of peripheral intravenous catheters: A randomised controlled equivalence trial. Lancet. 2012;380(9847):1066-74. https://doi. org/10.1016/s0140-6736(12)61082-4

PMid:22998716

16. Arbaee I, Mohd Ghazali A. Nurses knowledge and practice towards care and maintenance of. Qualitative Research. 2016 [Cited 2020 Sept 22];1(3):385-405. Available from: https:// www.researchgate.net/profile/Ahmad-Nizal-Mohd-Ghazali/ publication/236982617_Nurses_Knowledge_and_Practice_ Towards_Care_and_Maintenance_of_Peripheral_Intravenous_ Cannulation_in_Pantai_Hospital_Batu_Pahat_Johor_Malaysia/ links/Odeec51 aaccac0ffe $7000000 /$ Nurses-Knowledge-andPractice-Towards-Care-and-Maintenance-of-Peripheral-
Intravenous-Cannulation-in-Pantai-Hospital-Batu-Pahat-JohorMalaysia.pdf

17. Smith SJ, Roehrs CJ. High-fidelity simulation: Factors correlated with nursing student satisfaction and self-confidence. Nurs Educ Perspect. 2009;30(2):74-8. PMid:19476068

18. Jones P, Rai BP. The status of bedside teaching in the United Kingdom: The student perspective. Adv Med Educ Pract. 2015;6:421-9.

PMid:26082672

19. McGee S. A piece of my mind. Bedside teaching rounds reconsidered. JAMA. 2014;311(19):1971-2. https://doi. org/10.1001/jama.2013.286201

PMid:24846031

20. Mohamadirizi S, Mardanian F, Torabi F. The effect of direct observation of procedural skills method on learning clinical skills of midwifery students of medical sciences. J Educ Health Promot. 2020;9:91. https://doi.org/10.4103/jehp.jehp_672_19 PMid:32509899

21. Mughal Z, Noory S: Increasing medical students' confidence in procedural skills using a junior doctor-delivered bedside supervision program. Teach Learn Med. 2015;27:417-21. https://doi.org/10.1080/10401334.2015.1077130 PMid:26508000

22. Salah AB, El Mhamdi S, Bouanene I, Sriha A, Soltani M. Patients' attitude towards bedside teaching in Tunisia. Int J Med Educ. 2015;6:201-7. https://doi.org/10.5116/ijme.5669.ea24 PMid:26706313

23. McGaghie WC, Issenberg SB, Cohen ME, Barsuk JH, Wayne DB. Does simulation-based medical education with deliberate practice yield better results than traditional clinical education? A meta-analytic comparative review of the evidence. Acad Med 2011;86(6):706-11. https://doi.org/10.1097/ acm.0b013e318217e119

PMid:21512370

24. Kaddoura MA. New graduate nurses' perceptions of the effects of clinical simulation on their critical thinking, learning, and confidence. J Contin Educ Nurs. 2010;41(11):506-16. https:// doi.org/10.3928/00220124-20100701-02 PMid:20672760

25. Thomas C, Mackey E. Influence of a clinical simulation elective on baccalaureate nursing student clinical confidence. J Nurs Educ. 2012;51(4):236-9. https://doi. org/10.3928/01484834-20120224-03 PMid:22356359

26. Tiffen J, Graf N, Corbridge S. Effectiveness of a lowfidelity simulation experience in building confidence among advanced practice nursing graduate students. Clin Simul Nurs. 2009;5(3):e113-7. https://doi.org/10.1016/j.ecns.2009.01.009

27. Brown D, Chronister C. The effect of simulation learning on critical thinking and self-confidence when incorporated into an electrocardiogram nursing course. Clin Simul Nurs. 2009;5(1):e45-52. https://doi.org/10.1016/j.ecns.2008.11.001

28. Lilly ML, Hermanns M, Crawley B. Clinical simulation in psychiatric-mental health nursing: Post-graduation follow up. J Psychosoc Nurs Ment Health Serv. 2016;54:40-6. https://doi. org/10.3928/02793695-20160920-07 PMid:27699425

29. Bland AJ, Topping A, Wood B. A concept analysis of simulation as a learning strategy in the education of undergraduate nursing students. Nurse Educ Today. 2011;31(7):664-70. https://doi. org/10.1016/j.nedt.2010.10.013 PMid:21056920

30. Berragan L. Learning nursing through simulation: A case study 
approach towards an expansive model of learning. Nurse Educ Today. 2014;34(8):1143-8. https://doi.org/10.1016/j. nedt.2014.03.005

PMid:24713128

31. Jones T. Outcome measurement in nursing: Imperatives, ideals, history, and challenges. Online J Issues Nurs. 2016;21(2):1.

PMid:27854419

32. Khanghahi ME, Azar FEF: Direct observation of procedural skills (DOPS) evaluation method: Systematic review of evidence. Med J Islam Repub Iran. 2018;32:45. https://doi.org/10.14196/ mjiri.32.45

PMid:30159296

33. Barr J, Graffeo CS. Procedural experience and confidence among graduating medical students. J Surg Educ. 2016;73(3):466-73. https://doi.org/10.1016/j.jsurg.2015.11.014

PMid:26778743

34. Karim JA, Marwan YA, Dawas AM, Akhtar S. Self-confidence of medical students in performing clinical skills acquired during their surgical rotation. Saudi Med J. 2012;33(12):1310-6.

PMid:23232679

35. Kumar N, Singh Nk, Rudra S, Pathak S. Effect of formative evaluation using direct observation of procedural skills in assessment of postgraduate students of obstetrics and gynecology: Prospective study. J Adv Med Educ Prof. 2017;5(1):1-5.

PMid:28124015 